\title{
ARTICLE
}

\section{Radiation Protection Studies for ESS Superconducting Linear Accelerator}

\author{
Daniela ENE ${ }^{1,2, *}$, Mathias BRANDIN ${ }^{1}$, Mohammad ESHRAQI ${ }^{1}$, \\ Mats LINDROOS ${ }^{1}$, Steve PEGGS ${ }^{1}$ and Hakan HAHN ${ }^{1}$ \\ ${ }^{1}$ European Spallation Source ESS AB, P.O. Box 117, Stora Algatan 4, SE-221 00 Lund, Sweden \\ 2 "Horia Hulubei"National Institute for Physics and Nuclear Engineering, \\ P.O. Box MG-6, 76900, Bucharest, Romania
}

\begin{abstract}
This paper reports first estimates of the radiation protection shielding required for the ESS machine and provides a preliminary characterization of the residual radiation field inside the accelerator tunnel.

Two scenarios were analyzed: (a) an accidental full beam loss during $1 \mathrm{~s}$ every day and (b) continuous beam loss of $1 \mathrm{~W} \mathrm{~m}^{-1}$, representing normal operation conditions. Representative loss positions along the accelerator at various energies were investigated using a simplified geometry model of the linac to asses the lost proton beam prompt radiation field. Dedicated Monte Carlo (MC) simulations with the PHITS and MCNPX2.6.0 codes were performed to analyze the propagation of neutrons through the tunnel shield wall and its surroundings. The induced radioactivity in the accelerator components, concrete walls, and air inside the tunnel were estimated using the DCHAIN and CINDER'90 codes based on the external neutron source and spallation products derived from MCNPX. Ambient dose equivalent rates due to the residual radiation were calculated with the MCNPX code using photon sources resulting from CINDER.
\end{abstract}

KEYWORDS: accelerator, Monte Carlo, shielding, activation, radioactive wastes

\section{Introduction}

In May 2009, a number of European countries reached the consensus that Lund, Sweden, will be the site of the European Spallation Neutron Source (ESS). ESS will be the world leading accelerator driven long pulse neutron scattering facility. One of the goals of the ESS is to deliver to the sample at least one order of magnitude more neutrons per pulse in the relevant wavelength range beyond the capabilities of the current sources or those under construction. The intense beams as well as the accessibility to longer-wavelength (colder) neutrons will provide new opportunities opening a broad field of areas of science. The key experiments envisaged in the science case of $\mathrm{ESS}^{1)}$ will allow investigating important topics like: soft matter, magnetism, disordered materials, powdered diffraction, biological materials, neutron physics, chemical spectroscopy as well as polymer and protein dynamics. These scientific opportunities within ESS are basic researches answering to main humanity problems like: health, soft matter, energy, IT and process efficiency.

The proposed schematic layout of the ESS facility is based on a linear accelerator (linac) directing the proton beam on a target where neutrons are produced via spallation reactions. Further the neutrons will be moderated to thermal and subthermal energies in a couple of moderators placed around the target. The moderators feed 22 beamlines guiding the neutrons to the scattering instruments, mainly for neutron

*Corresponding author, E-mail: Daniela.ene@esss.se

(C) 2011 Atomic Energy Society of Japan, All Rights Reserved. scattering research. According to the 2010 ESS baseline design, the linac will deliver $5 \mathrm{MW}$ of $2.5 \mathrm{GeV}$ protons to a single target, in $2 \mathrm{~ms}$ long pulses with a $20 \mathrm{~Hz}$ repetition rate. The aims of these radioprotection-safety studies are:

1) To develop a radioprotection-safety assessment approach, based on the current knowledge and understanding of the ESS accelerator.

2) To assess the level of accelerator system radioprotection-safety using currently available information.

The assessment relates mainly to the normal operation accelerator safety performance and addresses the released activity level required in the assessment of the potential radiological impact upon the environment during the normal running practice.

\section{Calculation Procedure}

\section{Design Requirements}

In agreement with the Swedish legislation ${ }^{2)}$ and the IAEA recommendations ${ }^{3)}$ the dose equivalent rate limit for normal operation was taken to be $0.1 \mu \mathrm{Svh}^{-1}$ for public areas, $3 \mu \mathrm{Svh}^{-1}$ for supervised areas and $10 \mu \mathrm{Svh}^{-1}$ for controlled areas.

These values ensure that the annual dose equivalent limits of $1 \mathrm{mSv}$ for the public and $20 \mathrm{mSv}$ for the workers for an operation time of $2000 \mathrm{~h} \mathrm{y}^{-1}$ will not be exceeded. A shielding design was proposed for each classified area mentioned above.

An accident scenario considers a full beam loss $\left(1.248 * 10^{16}\right.$ protons per second) at a single point that cor- 
responds to a maximum loss of the $5 \mathrm{MW}$ beam $(2.5 \mathrm{GeV})$. The design requirement for a full beam loss used in CERN ${ }^{4}$ states that a full beam loss at a localized point must not give rise to a dose equivalent rate outside the shielding higher than $100 \mathrm{mSvh}^{-1}$ providing that the accelerator control system is able to abort the beam in a time given rise to an integral dose that remains under permissible limit for any worker. This safe limit was fixed to $50 \mu \mathrm{Sv}$ in accordance with the regulations of the majority of countries involved in the ESS project.

Note that a proposal for the ESS shielding design policy providing project-level shielding design criteria more stringent than the minimum Swedish legislation requirements is now under analysis. This is necessary because margins are needed for calculation and design uncertainties. Additionally, during the detailed design, provisions have to be taken to demonstrate that ESS personnel exposures will be as low as reasonably achievable (ALARA). Until these safety design requirements will be approved by the Swedish Nuclear Authority the conservative assumption of a safety factor of 3 in the shielding design was applied. That was obtained by increasing the thickness of the shielding by $1.1 * \lambda$ ( $\lambda$ is the neutron's attenuation length).

\section{Radiation Sources}

Two situations were analyzed for the shielding calculations: i) normal linac operation and ii) accidental full beam loss. The expected integrated equivalent dose from full beam loss outside the predicted shields has to comply with the limit $(50 \mu \mathrm{Sv})$ in case of a cut-off time of $50 \mathrm{~ms}$, a value provided by accelerator designers. ${ }^{5)}$

For beam losses during routine operation the designers of the accelerator have provided a guideline value of less than $1 \mathrm{Wm}^{-1}$. This value correspond to beam losses of $6.24 * 10^{12} / \mathrm{E}(\mathrm{E}$ in $\mathrm{MeV}$ ) protons per meter and per second.

\section{Design Assumptions}

The strategy to design the radiation shield for the linac was based on two assumptions.

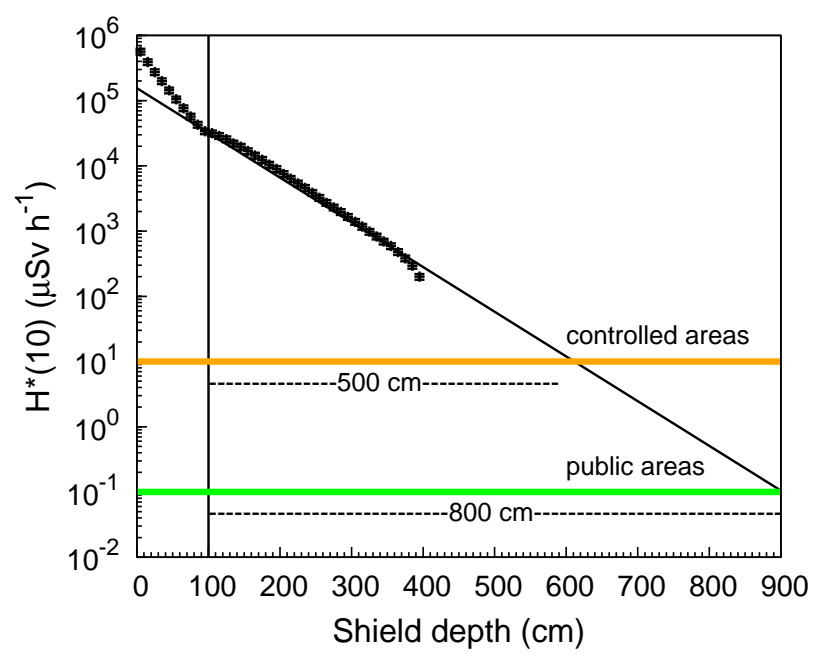

First, the uniform loss over a length of about $10 \mathrm{~m}$ was assumed to be equivalent to a constant loss concentrated at a single point having 10 times more intensity. ${ }^{6}$ Thus the beam losses during operation were represented by point losses concentrated at defined position along the machine of $6.24 * 10^{13} / \mathrm{E}(\mathrm{E}$ in $\mathrm{MeV})$ protons/s in case of the beam loss scenario. Based on this first hypothesis a simple model was used to estimate the lateral shielding required for linac. The codes PHITS $^{7)}$ and MCNPX $^{8)}$ version 2.6.0 Monte Carlo codes were used to simulate the protons transport through this model and calculate the equivalent dose rates spatial distributions $\mathrm{H}^{*}(10)$ in the specified shield geometry. The resulted neutron attenuation curves in concrete were fitted by an exponential function approach ${ }^{9)}$ developed for transmission of secondary neutrons generated by protons. The equivalent dose rate $\mathrm{H}^{*}(10)$ was approximated by the following attenuation formula:

$$
H(\theta, d / \lambda)=\frac{H(\theta)}{r^{2}} \exp \left(\frac{-d}{\lambda, \theta}\right),
$$

where $r$ and $\theta$ are the spherical coordinates of the current point where the dose rate is measured and $\mathrm{d}$ is the total distance transversed by the radiation in the shielding material. The parameters , $\lambda_{\theta}$ are the source term and the attenuation length for the large-depth exponential function which models the equilibrium status reached.

Making use of Eq. (1) the above mentioned parameters were fitted $\left(\theta=90^{\circ}\right)$ for subsequent determination of the shield thickness needed to attenuate the radiation dose by the desired factor.

The second basic design assumption ${ }^{4)}$ states that a shield designed for a continuous loss during the routine operation is also adequate for an accident loss of a full beam at a localized point providing that the linac cut-off time is short enough to produce an integrated dose below the acceptable limit.

Consistent with the above assumption the estimation of the lateral shielding of the linac is illustrated in Fig. 1.

The reference tunnel shielding, consists of one meter of

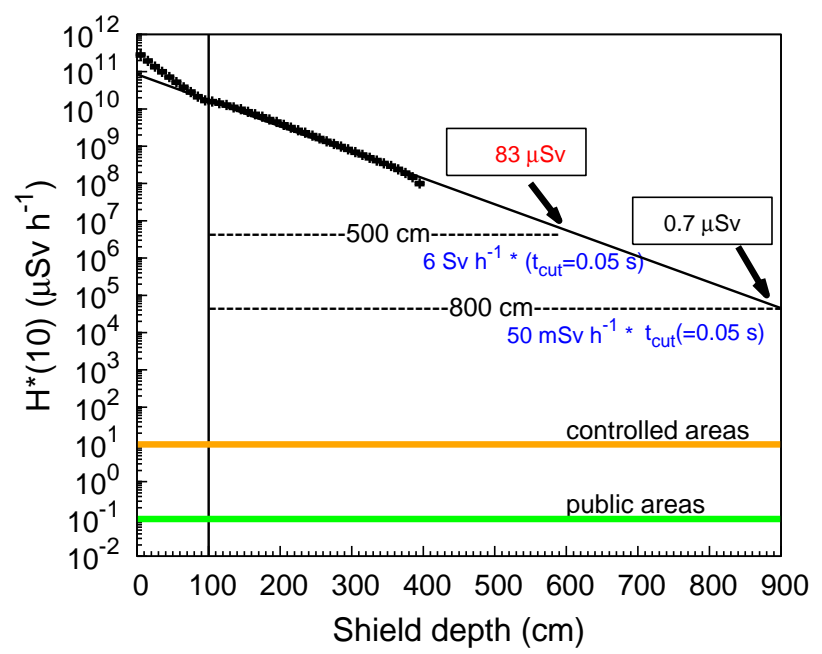

Fig. 1 Neutron dose rate attenuation curves in the concrete wall of the linac tunnel corresponding to $2.5 \mathrm{GeV}$ proton beam energy (left) and full beam loss (right). In the figure, points represented the resulted PHITS attenuation profile while continuous line represent the curve fitted using the analytical formula. 
ordinary concrete plus subsequent soil layer. Derived dry soil thicknesses required to meet the design constraints are included to demonstrate that the expected integrated equivalent dose from full beam loss outside the predicted shields complies with the set cut-off time limit. The results for the high energy zone of the linac are presented. It is apparent from the figure that for one meter concrete and subsequent derived soil shield $(8 \mathrm{~m})$ required to meet the public area limit, the integral equivalent dose arising from the full beam loss in $50 \mathrm{~ms}$ is below the limit $(50 \mu \mathrm{Sv}$ considered in this study). While for the soil shield thickness of $5 \mathrm{~m}$ derived to meet the controlled area criterion (see left panel of Fig. 1) the integral dose in case of a full beam accident is greater than the criterion and therefore not acceptable.

\section{Description of the Simulations}

In this initial stage of the design a simplified geometry was adopted. The lost protons were assumed to strike a thick copper target $(5 \times 5 \times 5) \mathrm{cm}^{3}$ that approximates the copper structure of the quadruples or the cavity. A rectangle concrete shell with cross section of $(300 \times 400) \mathrm{cm}$ having $100 \mathrm{~cm}$ thickness was used to simulate the tunnel walls. The beam axis was placed asymmetrically (100 cm from one side) inside the tunnel. A $300 \mathrm{~cm}$ thick soil layer was placed outside the tunnel concrete walls. The total width of the shielding structure was set to $10 \mathrm{~m}$. The loss location was also asymmetrically modeled along the beam line, allowing $600 \mathrm{~cm}$ length in the forward direction. Compositional data, nuclide content and impurity elements present within the component materials have been chosen as follows:

- GLIDCOP Al-25 $5^{10}$ ( $\rho=8.85 \mathrm{~g} \mathrm{~cm}^{-3}$ ) for Cu target: $\mathrm{Cu}$ 99.49\%, Al 0.25\%, O 0.22\%, B 0.025\%, Se 0.003\%, Fe $0.002 \%$, Te $0.002 \%$, S 0.001\%, Zn 0.001\%, Sb 0.001\%, As $0.001 \%$, Pb $0.001 \%$, Sn $0.0009 \%$, Mn $0.0002 \%$, P $0.0002 \%$, Bi $0.0002 \%$, Cd 0.0001\%;

- ordinary concrete ${ }^{11)}\left(\rho=2.3 \mathrm{~g} \mathrm{~cm}^{-3}\right)$ chemical composition of the research reactor ULYSSE (CEA Saclay): O 52.9\%, Si $21.8 \%$, Ca $17.4 \%$, C $3.7 \%$, Al 1.5\%, Fe $1 \%$, $\mathrm{K} 0.5 \%$, H $0.4 \%$, Na $0.4 \%$, Mg 0.3\%, S $0.1 \%$ and more than 70 other traces up to Uranium.

- air inside the tunnel ( $\rho=1.24375^{*} 10^{-3} \mathrm{~g} \mathrm{~cm}^{-3}: \mathrm{N}$ 75.558\%, O 23.159\% and Ar 1.283\%;

- soil surrounding the tunnel, a composition derived from several soil-samples from Lund site location $\left.{ }^{12}\right)(\rho=1.6 \mathrm{~g}$ $\mathrm{cm}^{-3}$ ) : H $1.54 \%$, O 51.55\%, Na 0.61\%, Mg 0.78\%, Al 4.5\%, Si $28.8 \%$, P $0.05 \%$, K 1.91\%, Ca $8.06 \%$, Ti $0.24 \%$, Fe $1.96 \%$ including trace elements at the level of ppm.

PHITS code uses an intranuclear cascade model to simulate nucleon-induced reactions and a model based on QMD theory for reactions induced by both nucleons and heavy ions. Statistical decay of compound nucleus is calculated with GEM. ${ }^{13)}$ Dose rates conversion factors used by the code are given in Reference 14. In the present calculations default option standing for Bertini intranuclear (INC) cascade is applied.

The splitting/importance variance technique was used for the PHITS/MCNPX simulations based on the geometry model described above. The nuclear data library underlying all present simulations is based mainly on the ENDF/B VII evaluated file. In order to obtain results with reasonable low uncertainty $10^{7}$ histories were tracked in all simulations.

For activation analysis PHITS was coupled with DCHAIN-SP. ${ }^{15)}$ MCNPX $^{8)}$ photon transport simulations were further carried out to estimate the ambient dose equivalent rates at surface and at one meter distance from the irradiated element.

\section{Results and Discussion}

\section{Shielding Configurations}

The shielding study was focused on a shielding configuration of one meter concrete tunnel wall and subsequent soil layer. From the analysis of results shown in Fig. 1 the additional soil layer thickness required to reduce the integral dose below the acceptable criterion are given in Table 1 .

Dose rates profile across the tunnel in the high energy beam transport zone (HEBT) of the accelerator devoted to connect the beam to the target and upgrading were also derived. In simulations a composite shield block of two meters of iron and subsequent one meter of ordinary concrete was used. In the model the shielding was placed one meter far from the loss point.

Table 1 Estimated thickness of the soil layer

\begin{tabular}{ccc}
\hline $\begin{array}{c}\text { Limit } \\
\left(\mu \mathrm{Sv} \mathrm{h}{ }^{-1}\right)\end{array}$ & $\begin{array}{c}\text { Soil thickness to meet } \\
\text { the criterion for 10 W } \\
\text { point beam loss }(\mathrm{cm})\end{array}$ & $\begin{array}{c}\text { Integral dose } \\
\text { from full beam } \\
\text { loss }(\mu \mathrm{Sv})\end{array}$ \\
\hline 10 & 500 & 83 \\
3 & 588 & 18 \\
1 & 658 & 6 \\
0.1 & 800 & 0.7 \\
\hline
\end{tabular}

Corroborating the obtained results one can conclude that two meters of iron block followed by $40 \mathrm{~cm}$ of ordinary concrete layer will be required to shield the bending magnet in the linac to target connecting zone. It should be noted that additional evaluation considering backscattering of the neutrons from the target area are necessary to size correctly the magnet shielding for ensuring the working conditions in the area.

\section{Residual Field Inside the Tunnel}

Activation results for copper target and for the inner wall concrete $20 \mathrm{~cm}$ stratum are provided in Fig. 2 as specific activities at $2.5 \mathrm{GeV}$ proton beam loss energy. The dominant nuclides representing more than $90 \%$ from the total activity are shown as well. The duration of an experimental campaign, 50 days of irradiation was analyzed.

A high total activation value of $5.2 * 10^{7} \mathrm{Bqcm}^{-3}$ coming from accelerator structure at 1 hour decay time is due to ${ }^{64,62,61,65} \mathrm{Cu}$ radionuclides while at long decay times ${ }^{59} \mathrm{Fe},{ }^{60} \mathrm{Co},{ }^{3} \mathrm{H}$ and ${ }^{63} \mathrm{Ni}$ dominate. The main contributor at short times is ${ }^{64} \mathrm{Cu}$ produced from thermal neutron capture in ${ }^{63} \mathrm{Cu}$ (high activation cross section of 4.5 barn). 

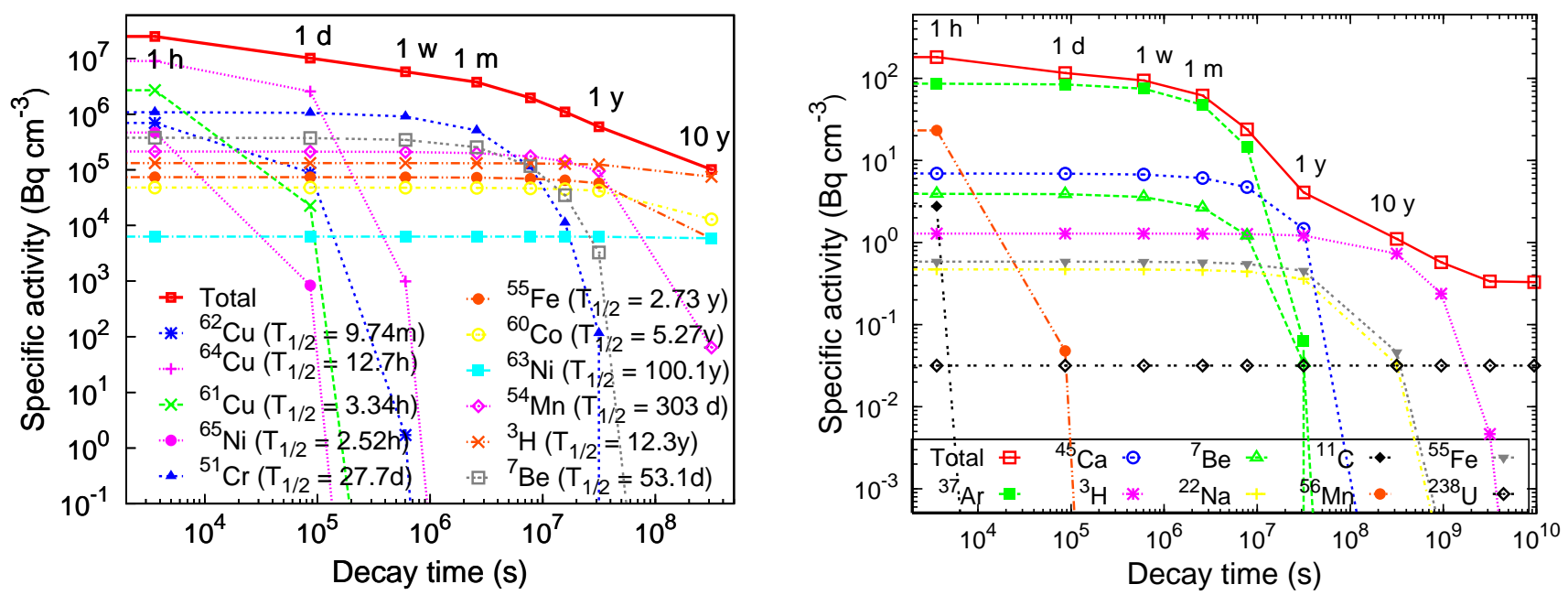

Fig. 2 Obtained specific activity distributions versus decay time after 50 days of irradiation. On the left are presented: dominant radionuclides produced in case of the copper target and for the inner $20 \mathrm{~cm}$ layer of concrete (right). Results correspond to $2.5 \mathrm{GeV}$ proton loss energy.
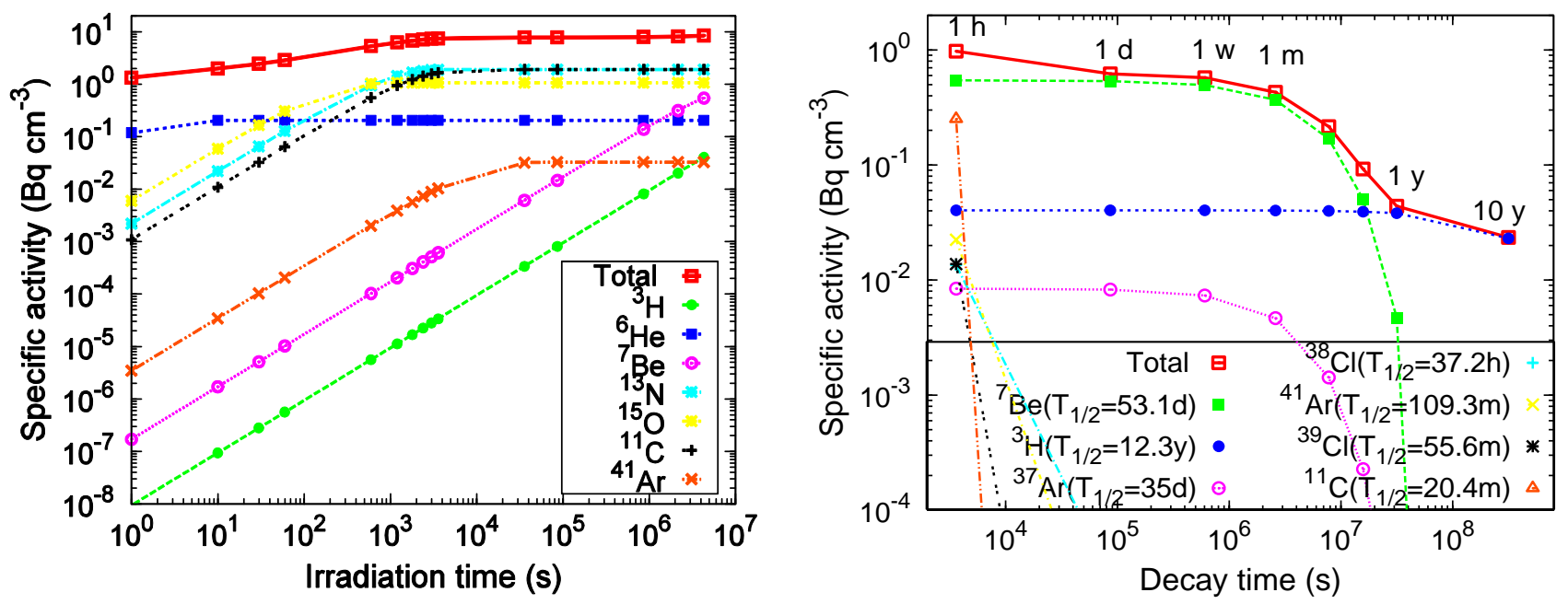

Fig. 3 Obtained specific activity of one $\mathrm{m} 3$ of air surrounding the beam loss inside the tunnel for 50 days of irradiation. Build-up of the radionuclide activation with the irradiation time (left) and beam-off activity distributions as a function of decay times (right). Results correspond to $2.5 \mathrm{GeV}$ proton loss energy.

The contribution of the tunnel concrete wall to the total activity is not significant. Concrete contains $0.4 \%$ of sodium which results in thermal neutron produced ${ }^{24} \mathrm{Na}$, being the major contributor to the dose rates near the walls, shortly after the beam is switched off.

The ${ }^{37} \mathrm{Ar}$ isotope issuing from $\mathrm{Ca}$ activation dominates the concrete activity until 6 months while for longer decay time ${ }^{3} \mathrm{H}$ and further ${ }^{238} \mathrm{U}$ together with its ascendants become majority giving rise nevertheless to a small activity value.

The decay time distribution of the specific activity in concrete depth until $100 \mathrm{~cm}$ with layers of $20 \mathrm{~cm}$ thickness scales approximately as is further depicted in the right panel of Fig. 4 for 40 years of operation.

The estimated air activity (see Fig. 3) is much less than the activation of the materials in the tunnel. Thus associated exposure by air inhalation is expected to be much lower with respect to the external doses coming from accelerator structure. In the figure the results correspond to one cubic meter of the air surrounding the proton beam loss at the end segment of the accelerator $(2.5 \mathrm{GeV})$. Shown estimates were derived for an irradiation history of 50 days.

Radioactive isotopes in the air surrounding the beam loss are the short-lived positron emitters that are produced in oxygen and nitrogen by spallation reactions $\left(\mathrm{T}_{1 / 2}\right.$ few minutes). ${ }^{7} \mathrm{Be}$ and ${ }^{3} \mathrm{H}$ are produced by spallation reactions while ${ }^{41} \mathrm{Ar}$ by thermal neutron capture in the natural argon. The left panel of Fig. 3 shows the saturation effect occurring for short lived radionuclides in the air during the irradiation. Long lived nuclides ${ }^{7} \mathrm{Be}$ and ${ }^{3} \mathrm{H}$ do not reach saturation in 50 days of operation. One hour after the operation shut-down time ${ }^{7} \mathrm{Be}$ and ${ }^{11} \mathrm{C}$ are the main radionuclides produced in the air giving rise to a total activation of about $1 \mathrm{~Bq} \mathrm{~cm}^{-3}$. Predicted dose rates after activation are given in Table 2 for high energy zone of the tunnel.

Residual dose levels obtained in these preliminary calculations are high. One hour after shut-down in the high energy 

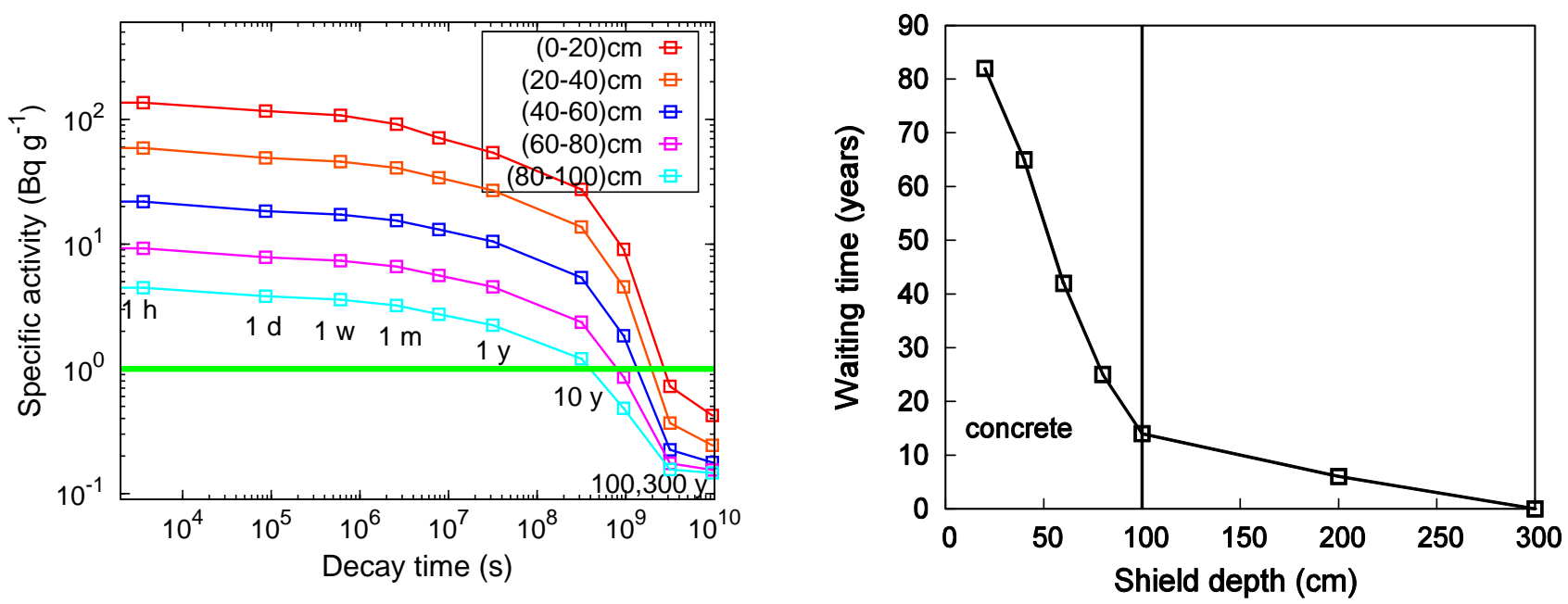

Fig. 4 Left: residual activity as a function of the wall concrete thickness after 40 y operation at 0.7 duty cycle. Sample from high energy zone is shown. The green line stands for the exemption limit. Right: waiting time before the induced radioactivity in the shielding decreases below the exemption limit, as a function of depth in the concrete and soil.

Table $2 \mathrm{H}^{*}(10)$ in $\mu \mathrm{Svh}^{-1}$ inside the tunnel corresponding to the high energy zone $(2.5 \mathrm{GeV})$

\begin{tabular}{ccccc}
\hline $\begin{array}{c}\text { Time } \\
{[\mathrm{h}]}\end{array}$ & \multicolumn{2}{c}{ 1 m in air } & \multicolumn{2}{c}{ Contact } \\
& target & $\begin{array}{c}\text { Concrete } \\
\text { wall }\end{array}$ & $\begin{array}{c}\text { Cu } \\
\text { target }\end{array}$ & $\begin{array}{c}\text { Concrete } \\
\text { wall }\end{array}$ \\
\hline 1 & 182 & 12 & $310^{5}$ & 37.50 \\
24 & 85 & 3 & $1.510^{5}$ & 9.44 \\
168 & 53 & 0.6 & $910^{4}$ & 2.46 \\
720 & 30 & 0.2 & $510^{4}$ & 0.61 \\
4320 & 8 & 0.01 & $1.410^{4}$ & 0.16 \\
\hline
\end{tabular}

zone of the accelerator, dose rates of few hundreds of $\mu \mathrm{Svh}^{-1}$ were found. These radiation levels are about four orders of magnitude smaller than the operational doses estimated one meter from the loss point. As resulted from this table the residual activation field inside the tunnel is arising mainly from copper structure activation. The concrete wall contribution is negligible $(<10 \%)$. Even though the decaying of the short lived radionuclides like ${ }^{61} \mathrm{Cu},{ }^{60} \mathrm{Cu},{ }^{24} \mathrm{Na}$ drops the dose rate close to the target to a factor 2 after one day of cooling, due to the contribution of the other long lived relevant nuclides $\left({ }^{60} \mathrm{Co},{ }^{54} \mathrm{Mn},{ }^{55} \mathrm{Fe},{ }^{7} \mathrm{Be}\right)$ the dose rate remains high.

In the high energy zone of the linac continuous accessibility inside the tunnel in the beam-off stage is possible after more than one month cooling time. If intervention is required earlier an occupancy factor of minimum 10 hours per year allows meeting the constraint of $2 \mathrm{mSv}$ per person and per intervention, the criterion used in $\mathrm{CERN}^{16)}$ or the design of the nuclear facilities.

Contact dose rate values significantly higher than the limits show that a remote system for handling and transportation of the dismantled component might be considered. The contact dose is higher than $10 \mathrm{mSvh}^{-1}$ for an item extracted from the accelerator structure in the high energy zone even after six months cooling time.
Consistent with the above analysis the high energy end of the linac might be classified as radiation controlled area with restricted access. Therefore the access and transportation paths should be set-up in order to protect the personnel during handling operations.

\section{Radioactive Waste, Concrete and Soil Shielding}

The induced radioactivity in the concrete wall of the linac tunnel was calculated for each $20 \mathrm{~cm}$ thick layer of concrete. Figure 4, left side gives the total specific activity in the five layers of the concrete wall. Note that for soil the ${ }^{40} \mathrm{~K}$ activation was not accounted.

The above mentioned figure shows values after 40 years of continuous operation at 0.7 duty cycle followed by different cooling times until 300 years. Activation in the concrete wall decreases with almost a factor 2 for each $20 \mathrm{~cm}$ of depth. At the shut-down of the installation (40 years of irradiation) one meter layer of concrete shield will have a radioactivity exceeding the exemption limit. For these considerations was chosen as exemption limit of $1 \mathrm{~Bq} \mathrm{~g}^{-1}$, a general agreed figure ${ }^{17)}$ used to classify clearance of the radioactive waste. Clearance is defined as the removal of the radioactive materials or radioactive objects within the authorized practices from any further regulatory control by the regulatory body. The time required to wait until the concrete wall might be considered as exempt waste is shown in the right panel of Fig. 4.

The residual radioactivity of the soil layers surrounding the high energy zone of linac was scored also for the same irradiation history as above. The obtained results are shown in Fig. 5.

Activation concentrations scored inside first $20 \mathrm{~cm}$ at the entrance in each one meter soil layer are given in the figure.

Note the level of the specific activity in the first layer of soil at $1 \mathrm{~h}$ cooling higher than levels of the last two layers of the concrete shield at the same decay time.

Because the ${ }^{40} \mathrm{~K}$ activation value found in the first $20 \mathrm{~cm}$ of soil is below the exemption level ${ }^{17)}$ of $10 \mathrm{~Bq} \mathrm{~g}^{-1}$ one can 


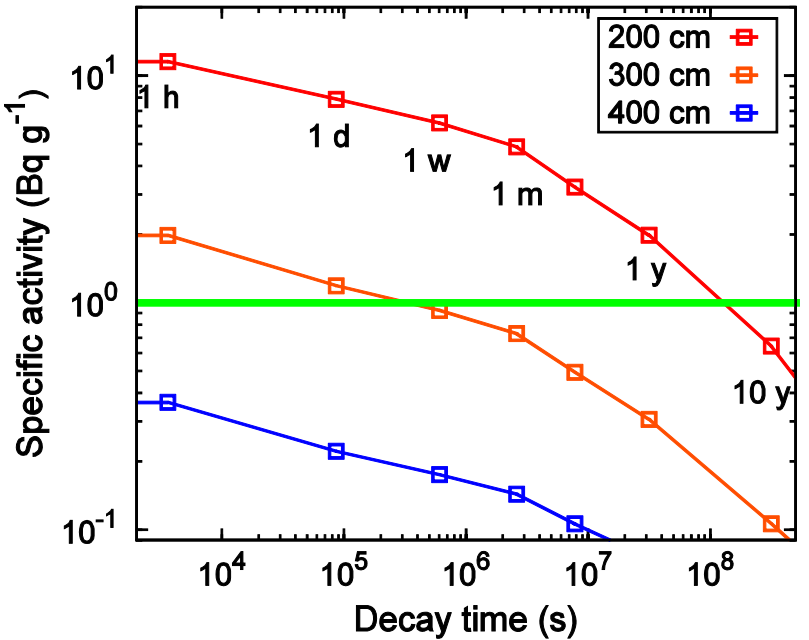

Fig. 5 Residual activity of the soil as a function of the thickness. The plot does not contain the contribution of ${ }^{40} \mathrm{~K}$.

characterize the soil as radwaste only by means of the other radionuclides.

The first two meters of soil in the vicinity of the accelerator has to be treated as nuclear waste, at least for 15 years. Dismantling and disposal of this large amount of soil is more difficult than similar operations for the concrete waste.

\section{Soil Activation and Potential Contamination of the Groundwater}

The results for the ten most important isotopes from the point of view of the environmental risk assessment ${ }^{18)}$ are shown in Table 3. Calculations have shown that most of these radionuclides are produced by spallation. In order to account for cumulative effect exposure periods of one year and 40 years of continuous operation with a duty factor of 0.7 were used for the activation analysis. In the table the third column shows the specific activity estimated at high energy end of the linac.

Column three of the table gives the integrated activation over the volume of the first soil layer calculated for the reference tunnel size (Volume $=7.07 * 10^{9} \mathrm{~cm}^{3}$ ) supposing that the soil is uniformly activated over the length of the accelerator as at the high energy end of the linac. In a conservative approach one can compare directly the radionuclide concentration in the soil with annual limits on intake (ALI) stipulated by the Swedish legislation ${ }^{2)}$ shown in the table. The results in the table indicate that for this conservative scenario only ${ }^{35} \mathrm{~S}$ does not represent any environmental hazard.

A less conservative comparison with the generic clearance levels for liquid release recommended by IAEA ${ }^{19)}$ leads to the conclusion that ${ }^{3} \mathrm{H}$, and ${ }^{45} \mathrm{Ca}$ are also unlikely to represent any off-site problem. A realistic evaluation of the environmental impact has to be done for the site of the facility.

Results of a hydro-geological study of the construction site and site specific data will provide a realistic evaluation of the exposure pathways as well as an accurate estimation of the fraction of the ground water that might reach the pub-
Table 3 Activity concentration in first $100 \mathrm{~cm}$ of soil surrounding the concrete wall after 40 years of continuous operation. Swedish ALI values are also provided for comparison.

\begin{tabular}{cccc}
\hline Nuclide & $\mathrm{T}_{1 / 2}$ & $\begin{array}{c}\text { Activity } \\
(\mathrm{Bq})\end{array}$ & $\begin{array}{c}\text { ALI } \\
(\mathrm{Bq})\end{array}$ \\
\hline${ }^{3} \mathrm{H}$ & $12.33 \mathrm{y}$ & $6.8410^{9}$ & $310^{9}$ \\
${ }^{7} \mathrm{Be}$ & $53.12 \mathrm{~d}$ & $6.9110^{8}$ & \\
${ }^{22} \mathrm{Na}$ & $2.60 \mathrm{y}$ & $1.0910^{9}$ & $210^{7}$ \\
${ }^{24} \mathrm{Na}$ & $14.96 \mathrm{~h}$ & $3.7810^{10}$ & $110^{8}$ \\
${ }^{32} \mathrm{P}$ & $14.26 \mathrm{~d}$ & $5.8910^{8}$ & $110^{7}$ \\
${ }^{35} \mathrm{~S}$ & $87.32 \mathrm{~d}$ & $4.1510^{7}$ & $810^{7}$ \\
${ }^{45} \mathrm{Ca}$ & $162.61 \mathrm{~d}$ & $7.4310^{9}$ & $310^{7}$ \\
${ }^{46} \mathrm{Sc}$ & $83.79 \mathrm{~d}$ & $1.4310^{9}$ & \\
${ }^{54} \mathrm{Mn}$ & $312.3 \mathrm{~d}$ & $1.1210^{9}$ & $310^{7}$ \\
${ }^{55} \mathrm{Fe}$ & $2.73 \mathrm{y}$ & $1.3710^{10}$ & $710^{7}$ \\
${ }^{65} \mathrm{Zn}$ & $244.26 \mathrm{~d}$ & $2.2310^{6}$ & \\
\hline
\end{tabular}

lic water supplies.

\section{Conclusion}

An approach (including both methods and tools) has been developed to assess the radioprotection-safety level of the ESS accelerator. Conservative assumptions, input parameters and tools used in this approach reflect the limited knowledge and understanding of the accelerator system, presently under preliminary design.

Monte Carlo simulations complemented with analytical predictions were used to estimate the thickness of the lateral shielding of the accelerator tunnel. A tunnel configuration placed underground in the earth is proposed as reference for further detailed evaluations. An ordinary concrete shielding wall of one meter thickness was considered in the analysis with the purpose of minimizing the activation of the soil surrounding the concrete. The size of the earth shielding following one meter of concrete was derived to meet the exposure criterion for controlled, supervised and public area. It was concluded from this investigation that a shielding thickness of about six meters of earth will be required for the option designating the site as supervised area and respectively eight meters of earth for public area designation.

Additionally, a preliminary estimate of the required shielding in the HEBT zone was performed. Calculations have shown that two meters of iron block followed by $40 \mathrm{~cm}$ of ordinary concrete layer will be required to shield the bending magnet in the linac to target connecting zone. This estimation accounts only for $1 \mathrm{~W} \mathrm{~m}^{-1}$ beam loss along the magnet and aims to reduce the prompt radiation to a level of $1 \mu \mathrm{Svh}^{-1}$. Additionally, it should be noted that evaluations considering backscattering of the neutrons from the target area are necessary to correctly size the magnet shielding for ensuring the working conditions in the area.

The proposed thickness of the shielding guarantees an integrated dose in case of accident that is below the acceptable limit with sufficient margin to cut off the beam.

The residual field inside the tunnel was further evaluated using a simple geometry to model unshielded beam loss consequences upon the machine structure, concrete wall and 
air inside. Residual dose levels obtained in these preliminary calculations are high. One hour after shut-down in the high energy zone of the accelerator, dose rates of few hundreds of $\mu \mathrm{Svh}^{-1}$ were found. Consistent with the obtained results the high energy end of the linac can be classified as radiation controlled area with restricted access.

Activation of the concrete wall and adjacent soil shielding was further estimated aiming at preliminary quantitative evaluation of the radioactive waste arising during the lifetime of the facility (40 years of operation). About $1.496 \times 10^{4}$ tones (volume of $6.365 \times 10^{3} \mathrm{~m}^{3}$ ) of concrete corresponding to the reference configuration of the tunnel will require final disposal. The first two meters of soil in the vicinity of the accelerator have to be treated as nuclear waste, at least for 15 years. The contamination of the adjacent soil is not avoided with the proposed increase of the thickness of the concrete tunnel wall. The radwaste soil has to be considered in the facility decommissioning waste management plan.

Release of radioactive materials into the environment was further assessed, guiding the evaluation and defining the potential sources for environmental contamination analysis, a major topic to be addressed by ESS design. Based on these estimations further complex studies are to be fulfilled to model the migration of the contaminant through the environment and to assess the impact.

Activity concentrations of radionuclides of major concern in terms of contaminant migration into the groundwater were derived for the first one meter of soil surrounding the concrete tunnel wall. The direct comparison of the obtained radionuclide concentration in the soil with annual limits for liquid release is too conservative to judge the environmental impact. Therefore a realistic evaluation based on site specific data will be needed.

\section{References}

1) ESS, http://ess-scandinavia.eu.

2) SSMFS2008:51, Stralsakerthetsmyndighetens foreskrifter om grundlaggande bestammelserfor skydd av arbetstagare och allmanhet vid verksamhet med joniserande stralning, Swedish Radiation Safety Authority (2008), [in Swedish].

3) IAEA, International Basic Safety Standards for Protection against Ionizing Radiation and for the Safety of Radiation
Sources, Safety Series No. 115, Vienna, (2004).

4) S. Agosteo, M. Silari, Preliminary shielding calculations for a $2 \mathrm{GeV}$ superconducting proton linac, Geneve: Technical report: TIS-RP/TM/2001-028, CERN (2001).

5) M. Eshraqi, Private communication, ESS-AB, Sweden (2010).

6) A. Fasso et al., Shielding against high energy radiation. Numerical data and functional relationships in science and technology, Berlin: Vol. 11, Ed. H. Shopper, Springer-Verlag (1990).

7) H. Iwase, K. Niita, T. Nakamura, J. Nucl. Sci. Technol., 39[11], 1142 (2002).

8) MCNPX, MCNPX Monte Carlo N-Particle Transport Code System for Multiparticle and High Energy Applications, http://mcnpx.lanl.gov

9) A. H. Sullivan, A Guide to Radiation and Radioactivity Levels Near High Energy Particle Accelerators, Nuclear Technology Publishing Ashford, TN23 1JW England, (1992).

10) D. G. Cepraga, Private communication, ENEA, Bologna, Italy (2007).

11) F. Aubert, Inventaire et Compositions Chimique des Matériaux du Réacteur ULYSSE de Saclay, DAPNIA/ SENAC/E/05-193/NT (2005).

12) Moormann, R. Private communication, FZJ Germany (2010).

13) S. Furihata et al., The GEM Code-A simulation program for the evaporation and fission process of an excited nucleus, JAERI-Data Code 2001-015, Japan Atomic Energy Research Institute (JAERI) (2001).

14) Y. Sakamoto, Y. Yamaguchi, Dose conversion coefficients in the Shielding Design Calculation for High Energy proton Accelerator Facilities, JAERI-Tech 2001-42, Japan Atomic Energy Research Institute (JAERI) (2001).

15) T. Kai et al., Induced radioactivity in J-PARC Spallation Neutron Source, JNM Supplement 4, (2004).

16) M. Sentis et al., "Calculation of intervention doses for the CNGS facility," Nucl. Instr. Meth. Phys. Res., A562[2], 985 (2006).

17) IAEA, Derivation of Activity Concentrations Values for Exclusion, Exemption and Clearance (2005).

18) R. H. Thomas, G. R. Stevenson, Radiological safety aspects of proton accelerators, Technical Reports Series No. 283, Vienna, IAEA (1988).

19) IAEA, Clearance of materials resulting from the use of radionuclides in medicine, industry and research, Vienna TECDOC-1000 (1998). 